\title{
Association of early neonatal-maternal outcomes with timing of elective caesarean section at term gestation
}

\author{
Priyanka Rohilla ${ }^{1}$, Poonam Goel ${ }^{1}$, Suksham Jain ${ }^{2 *}$
}

\begin{abstract}
${ }^{1}$ Department of Obstetrics and Gynaecology, ${ }^{2}$ Department of Neonatology, Government Medical College and Hospital, Chandigarh, India
\end{abstract}

Received: 12 April 2021

Accepted: 05 May 2021

\section{*Correspondence:}

Dr. Suksham Jain,

E-mail: dr.sukshamj@gmail.com

Copyright: $\odot$ the author(s), publisher and licensee Medip Academy. This is an open-access article distributed under the terms of the Creative Commons Attribution Non-Commercial License, which permits unrestricted non-commercial use, distribution, and reproduction in any medium, provided the original work is properly cited.

\begin{abstract}
Background: The decision for optimal time for elective caesarean section (ECS) should be taken considering the minimum risk to the newborn as well as to the mother. This prospective observational study aimed to investigate the effect of gestation of ECS, on neonatal and maternal outcomes.

Methods: All the pregnant term mothers admitted to our hospital for ECS and fulfilling the inclusion criteria were enrolled and divided into 2 groups, early term and full term. Patients having high-risk factors like intrauterine growth restriction, amniotic fluid disorders, multiple pregnancies, placenta previa, abruption placenta and medical comorbidities were excluded. Early neonatal and maternal outcomes were compared between the 2 groups.

Results: 244 mothers were eligible for ECS, 183 (75\%) women underwent ECS in the early term and $61(25 \%)$ at full term as per the decision of obstetricians of various units. The incidence of neonatal respiratory morbidity (NRM) was 2 percent in our study. Out of 244 newborns, 4 developed NRM in the form of delayed adaption in 3 and respiratory distress in 1 . The incidence of respiratory distress was comparable in both groups. The incidence of NNJ, MSL and sepsis was higher in the early term but it was not significant statistically. Maternal outcomes like postpartum haemorrhage, the need for blood transfusion, bladder injury, thin scar, adhesions poorly formed LUS were observed in the early term but the difference was not significant.

Conclusions: More research needs to be done for optimization of timing of ECS.
\end{abstract}

Keywords: Maternal outcomes, NRM, ECS, Neonatal outcomes

\section{INTRODUCTION}

Caesarean section (CS) is one of the most commonly performed surgical interventions in obstetrics. The neonatal and maternal outcome depends on numerous factors among which mode of delivery and gestation age are the most important determinants. Recent systemic review and meta-analysis have concluded that newborn delivered by ECS is at a higher risk of developing respiratory complications in comparison to normal vaginal delivery (NVD). ${ }^{1}$ Changes taking place in NVD contributing towards smooth neonatal respiratory transition include upsurge of catecholamine, corticosteroid release, mechanical chest compression by the birth canal and expression of sodium channel on foetal lung epithelium., ${ }^{2,3}$ In ECS, lack of this catecholamine upsurge contributes to surfactant deficiency, making the neonatal transition more complex leading to increased incidence of NRM. NRM ranges from respiratory distress syndrome (RDS), transient tachypnea of the newborn (TTN) to respiratory failure warranting for admission to neonatal intensive care unit (NICU), affecting mother-child bond, increased cost of care owning to an extended hospital stay and complications from invasive procedures such as artificial ventilation. 
Evidence cited in the literature reveals that as the gestation age at birth increases, a decrease in respiratory morbidity can be seen. ${ }^{4-6}$ Although, foetal lung matures by 37 weeks, respiratory complications are found to be more prevalent in the early term group. ${ }^{4-6}$ Prefumo et al in their cohort study had evaluated the respiratory and other complication of the newborn, delivered by emergency CS at different gestation and observed that the prevalence of RDS was $3.4 \%$ at 37 weeks and $1 \%$ at 39 weeks and the composite adverse neonatal outcomes were $7.8 \%$ and $4.7 \%$ at 37 and 38 weeks, respectively. ${ }^{7}$ The patient may go into spontaneous labour during her waiting period for $\mathrm{CS}$, resulting in an emergency $\mathrm{CS}$ in substandard circumstance carrying more neonatal and maternal risk. In systemic review and meta-analysis by Yang et al., it was observed that the infant mortality rates were $1.7 \%$ and $9.8 \%$ in ECS and ECS, respectively. ${ }^{8}$ Incidence of febrile illness, wound dehiscence, endometritis, puerperal sepsis and re-laparotomy were higher in patients with emergency CS in comparison to ECS. ${ }^{8}$ Deferring CS till 39 weeks may lead to situations like spontaneous rupture of the membrane in malpresentations like breech, transverse lie leading to a high incidence of perinatal mortality and morbidity because of entrapment of head, birth asphyxia and cord prolapse. ${ }^{9}$ Therefore, guidelines issued by the national institute of care and excellence (NICE), and the Royal college of obstetricians and gynaecologists (RCOG) recommends deferring ECS in uncomplicated, singleton pregnancy until 39 weeks. ${ }^{10,11}$

Any maternal benefit of postponing ECS to 39 completed weeks has not been investigated adequately. ECS beyond 39 weeks in patients of previous CS is associated with complications like scar dehiscence and uterine rupture but CS before 39 weeks is associated with poorly developed lower uterine segment (LUS), more blood loss, and blood transfusion. ${ }^{12,13}$ Thus, due to the paucity of evidence in the Indian population, we conducted a prospective observational study in the present work, to establish the optimum gestation for ECS being having profound significance, with the least risk to mother and fetus, to make a rational decision on the timing of ECS.

\section{METHODS}

This prospective observational study was conducted in the department of obstetrics and gynaecology in collaboration with the department of paediatrics at Government medical college and hospital (GMCH), Chandigarh and enrolment of the patients were done from January 2016 to June 2017.

\section{Sample size}

Considering respiratory distress in odds of 1.5 with $95 \%$ confidence interval and alpha error of $5 \%$, we were needed 90 patients with a precision of $80 \%$.

Pregnant women with gestational age between 370/7$406 / 7$ weeks of gestation posted for ECS with previous
CS or previous uterine surgery, not willing or not qualifying for the trial of labour after CS (TOLAC) with malpresentation, bad obstetric history (BOH), cephalopelvic disproportion (CPD) and on maternal request were enrolled in the present study. Patients posted for ECS but having high-risk factors like intrauterine growth restriction, amniotic fluid disorders, multiple pregnancies, placenta previa, abruption placenta and medical co-morbidities like intrahepatic cholestasis of pregnancy, multiple gestations, hypertensive disorders, pregestational diabetes, epilepsy, liver disease and tuberculosis, gestational diabetes were not included.

Enrolment was started after approval by the institutional ethics committee at $\mathrm{GMCH}$, Chandigarh. The studied sample size was divided into 2 groups of ECS patients. Group 1 was early term (ET) comprised of patients with gestational age between 370/7 to 386/7 weeks and group 2 was full-term (FT) comprised of patients with gestational age between $390 / 7$ to $406 / 7$ weeks. ${ }^{15}$ The period of gestation (POG) was calculated based on the clinical history and the earliest ultrasound findings. Demographic details, obstetrics history and medical history were taken in detail as per pre-designed format. Details about the treatment history, antibiotic prophylaxis for CS, steroid course (dexamethasone $6 \mathrm{mg}$, 4 doses 12 hours apart or betamethasone $12 \mathrm{mg}, 2$ doses 24 hours apart) for lung maturity and all the investigations done in the antenatal period were recorded. Other than this, details about the type of anaesthesia, intra-operative details, and the course during hospital stay were also recorded during the present study.

Neonatal outcomes like respiratory distress, delayed adaptation, NICU admission, 5 minute Apgar score, hypoglycemia, sepsis, seizures and maternal outcomes including postpartum haemorrhage, bladder and bowel injury, anaesthetic complication or any other maternal and neonatal complications (till the time of discharge) were compared between the two groups.

\section{Statistical analysis}

Discrete categorical data were represented as either a number or a percentage. Regression analysis using ANOVA was performed and the odds ratio was calculated to compare various outcomes. Chi square test or Fischer's exact test was applied for categorical data depending on the sample size. All the calculations were two-tailed and were performed using IBM SPSS version 22. A $p$ value of $<0.05$ was considered statistically significant.

\section{RESULTS}

During the study period, 11,155 deliveries took place, out of which 244 patients fulfilling the inclusion criteria were included in the study. $183(75 \%)$ women underwent ECS in the early term (ET) $\left(37^{0 / 6}-38^{6 / 7}\right)$ group and $61(25 \%)$ in the full-term group (FT $39^{0 / 6}-40^{6 / 7}$ ). A flow chart showing 
the procedure for the recruitment of eligible patients has been shown in Figure 1. The demographic profile of the two groups is compared in Table 1.

A comparison of the neonatal outcomes between the two groups is shown in Table 2. The incidence of NRM was $2 \%$ in our study. Out of 244 newborns, 4 developed NRM in the form of delayed adaption in 3 and respiratory distress in 1.2 of these babies needed NICU admission. However, there was no statistically significant difference in the incidence of NRM between the two groups. $47 \%$ of the patients in the ET group received steroid course for lung maturity. Table 3 summarizes the comparison of maternal outcomes between the two groups. There was no statistical difference in maternal outcomes between the two groups.

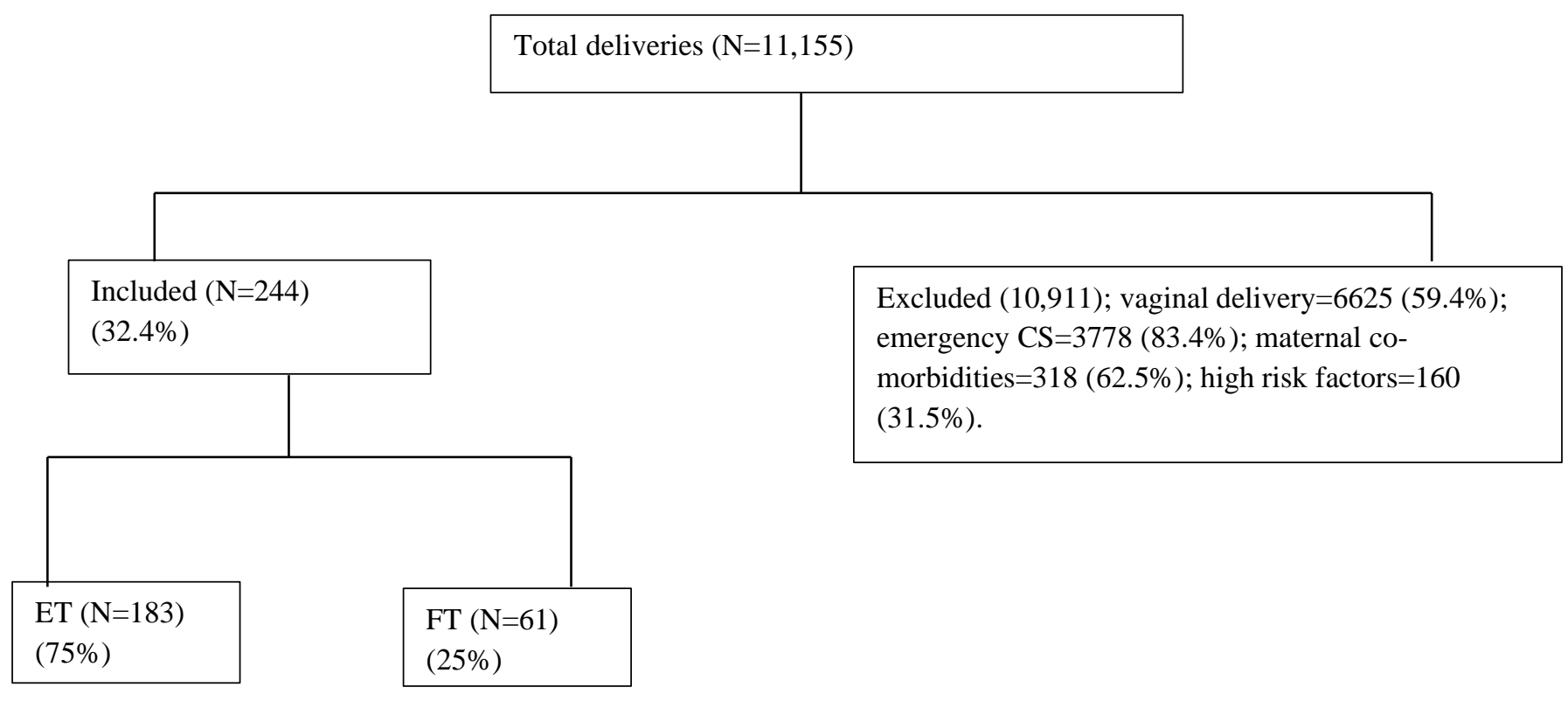

Figure1: Schematic diagram of the study group population.

Table 1: Demographic profile of the studied population.

\begin{tabular}{|c|c|c|c|c|}
\hline Characteristics & Categories & $\begin{array}{l}\text { Early term } \\
\text { (group 1) } \\
\mathrm{N}=183(\%)\end{array}$ & $\begin{array}{l}\text { Full term } \\
\text { (group 2) } \\
\mathrm{N}=61(\%)\end{array}$ & $P$ value \\
\hline Age mean $\pm S D$ (in years) & Mean age & $28.7 \pm 4.1$ & $27.6 \pm 3.5$ & 0.061 \\
\hline \multirow{4}{*}{ BMI $\left(\mathrm{kg} / \mathrm{m}^{2}\right)$} & Underweight $(<18.5)$ & $7(3.8)$ & $3(4.9)$ & \multirow{4}{*}{0.762} \\
\hline & Normal (18.5-22.9) & $44(24)$ & $18(29.5)$ & \\
\hline & Overweight (23-24.9) & $65(35.5)$ & $18(29.5)$ & \\
\hline & Obese $(>25)$ & $67(36.6)$ & $22(36.1)$ & \\
\hline \multirow{5}{*}{ Socioeconomic status } & Class 1 (upper) & $17(9.3)$ & $6(9.8)$ & \multirow{5}{*}{0.842} \\
\hline & Class2 (upper middle) & $72(39.3)$ & $22(36.1)$ & \\
\hline & Class3 (lower middle) & $61(33.3)$ & $21(34.4)$ & \\
\hline & Class 4 (upper lower) & $19(10.4)$ & $9(14.8)$ & \\
\hline & Class 5 (lower) & $14(7.7)$ & $3(4.9)$ & \\
\hline \multirow{4}{*}{ Religion } & Hindu & $119(65)$ & $48(78.7)$ & \multirow{4}{*}{0.205} \\
\hline & Muslim & $9(4.9)$ & $3(4.9)$ & \\
\hline & Sikh & $54(29.5)$ & $10(16.4)$ & \\
\hline & Christian & $1(0.5)$ & 0 & \\
\hline
\end{tabular}


Table 2: Comparison of neonatal outcomes in the two study group.

\begin{tabular}{|c|c|c|c|}
\hline Outcomes & $\begin{array}{l}\text { Group } 1 \text { early term } \\
\mathrm{N}=\mathbf{1 8 3}(\%)\end{array}$ & $\begin{array}{l}\text { Group } 2 \text { full term } \\
N=61(\%)\end{array}$ & P value \\
\hline Respiratory distress & $4(2)$ & 0 & 0.57 \\
\hline NNJ & $13(7.1)$ & $5(8.2)$ & 0.78 \\
\hline MSL & $6(3.2)$ & 0 & 0.341 \\
\hline Sepsis & $3(1.6)$ & 0 & 0.575 \\
\hline NICU ADMISSION & $2(1.09)$ & 0 & 1.00 \\
\hline Others (hypoglycemia, feeding difficulty) & $1(0.5)$ & 0 & 1.00 \\
\hline
\end{tabular}

Table 3: Comparison of maternal outcome in the two study groups.

\begin{tabular}{|llll|}
\hline Maternal outcomes & $\begin{array}{l}\text { Group 1 early term } \\
\text { N=183 }\end{array}$ & $\begin{array}{l}\text { Group 2 full term } \\
\text { N=61 (\%) }\end{array}$ & P value \\
\hline PPH & $3(1.6)$ & 0 & 0.575 \\
\hline Thin scar & $3(1.6)$ & $1(1.6)$ & 1.00 \\
\hline Bladder injury & $9(4.9)$ & $1(0)$ & 0.459 \\
\hline Poorly formed LUS & $1(0.5)$ & $0(0)$ & 1.00 \\
\hline
\end{tabular}

\section{DISCUSSION}

The incidence of NRM in our research was low (2\%) and it was only noticed in the early term (ET) group 1 . An observational comparative research conducted by Gisi et al and RCT conducted by Glavind et al compared neonatal outcomes when ECS was performed at $38-38^{6 / 7}$ versus $39-39^{6 / 7}$ and $38^{+3}$ versus $39^{+3}$ weeks, respectively and observed that the incidence of NRM was not statistically significant when ECS was done at 38 weeks or 39 weeks. $^{12,13}$ On the contrary, Shraddha et al in their retrospective study done in India noticed that the incidence of NRM was $15.8 \%$ and $6.3 \%$ in neonates, delivered at ET and full-term (FT) respectively $(\mathrm{p}=0.007){ }^{14}$ Another observational retrospective study performed by Sujata et al in Indian setup found that the incidence of NRM was $17.6 \%$ at 37 weeks, $5.6 \%$ at 38 weeks, $5.1 \%$ at 39 and $2.8 \%$ beyond 40 weeks. ${ }^{15}$ One of the reason for the low rate of NRM in our study might be because of the extensive steroid cover (as per RCOG guidelines) in the patients under study, planned for ECS before 39 weeks. Majority of the referenced studies are silent on steroid course for lung maturity if ECS was planned before 39 weeks. Evidence in the literature also reveals the early foetal lung maturation achieved in newborns of South Asian origin suggesting another reason accounting for the low incidence of NRM in the present study. ${ }^{16}$

Incidences of other adverse neonatal outcomes like jaundice, feeding difficulty, MAS, hypothermia in both the groups were statistically insignificant in the present study. Hourani et al and Okeke et al in their studies demonstrated that the complications like: hypothermia, feeding difficulty and jaundice are significantly higher if delivery is done before 39 weeks. ${ }^{17,18}$
There are limited studies at present, comparing maternal outcomes of ECS performed at various gestation of term pregnancy. The present study revealed that the incidences of complications like PPH and bladder injury were comparable when ECS was done at early term or full term. It was observed that LUS was not adequately formed when ECS was done at 38 weeks as compared to 39 weeks $(\mathrm{p}=0.0071)$ in an observational study by Gisi et al. ${ }^{12}$ RCT done by Glavind et al demonstrated that the composite maternal outcomes in the form of blood loss, bladder bowel injury, uterine rupture or dehiscence, procedural difficulty, uterine incision tear were not statistically significant $(\mathrm{p}=0.63)$ when ECS was performed at 38 weeks in comparison to 39 weeks. ${ }^{13}$

For all the enrolled patients under the present study, no maternal death, ICU admission, thromboembolic event were observed because of the low risk of developing intra-operative and post-operative complications, due to proper booking, supervision and uncomplicated pregnancy. A recent systematic review by Prediger et al studying the impact of ECS on maternal and neonatal health showed that neonatal respiratory complications and NICU admission decrease as the gestation approaches 39 weeks but again increases beyond $39^{+6}$ weeks. Due to limited studies on maternal outcomes, more research is required to make a balanced decision. ${ }^{19}$

\section{Limitations}

The study population of this study was small and we could not maintain records of the patients who had emergency CS during the waiting period for planned CS. These limitations can be overcome with the large multicentric study with a long duration of maternal and neonatal follow-up. 


\section{CONCLUSION}

Large multi-centric studies on the Indian population are needed for the timing of ECS in the best interest of the mother and the baby. This study didn't find any difference in neonatal and maternal morbidity at 37-38 weeks of gestation.

\section{Funding: No funding sources}

Conflict of interest: None declared

Ethical approval: The study was approved by the Institutional Ethics Committee

\section{REFERENCES}

1. Tefera M, Assefa N, Mengistie B, Abrham A, Teji K, Worku T. Elective cesarean section on term pregnancies has a high risk for neonatal respiratory morbidity in developed countries: a systematic review and meta-analysis. Front Pediatr. 2020;8:28698.

2. Gerten KA, Coonrod DV, Bay RC, Chambliss LR. Cesarean delivery and respiratory distress syndrome: does labor make a difference? Am J Obstet Gynecol. 2005;193:1061-4.

3. Olver RE. Of labour and the lungs. Arch Dis Child. 1981;56(9):659-62.

4. Finn D, O'Neill SM, Collins A, Khashan AS, O’Donoghue K, Dempsey E. Neonatal outcomes following elective caesarean delivery at term: a hospital-based cohort study. J Matern Neonatal Med. 2016;29(6):904-10.

5. Nakashima J, Yamanouchi S, Sekiya S, Hirabayashi M, Mine K, Atsushi Ohashi, et al. Elective cesarean section at 37 weeks is associated with the higher risk of neonatal complications. Exp Med. 2014;233(4):243-8.

6. Wilmink FA, Hukkelhoven CW, Lunshof S, Mol BW, Vander PJA, Papatsonis DN. Neonatal outcome following elective caesarean section beyond 37 weeks of gestation: a 7-year retrospective analysis of a national registry. Am J Obstet Gynecol. 2010;202(3):250-8.

7. Prefumo F, Ferrazzi E, Tommaso MD, Severi FM, Locatelli A, Chirico G. Neonatal morbidity after cesarean section before labor at $34+0$ to $38+6$ weeks: a cohort study. J Matern Fetal Neonat Med. 2016;29(8):1334-8.

8. Yang XJ, Sun SS. Comparison of maternal and fetal complications in elective and emergency cesarean section: a systematic review and meta-analysis. Arch Gynecol Obstet. 2017;296(3):503-12.

9. Adegbola O, Ayanbode O. The incidence, risk factors and determinants of perinatal outcome of umbilical cord prolapses in Lagos, Nigeria. Niger Med J. 2017;58(2):53-7.

10. Royal College of Obstetricians and Gynaecologists (RCOG). Antenatal Corticosteroids to Reduce Neonatal Morbidity and Mortality, 2010. Available at:

https://elearning.rcog.org.uk/sites/default/files/Preter m\%20labour/RCOG_Antenat_corticosteriod_GTG7 2010.pdf. Accessed on 28 March 2021.

11. National Institute of Health and Clinical Excellence (NICE): Caesarean section 2021. Available at https://www.nice.org.uk/guidance/ng192. Accessed on 6 April 2021.

12. Sebastian G, Ghose S, Soundararajan P. Comparison of maternal and neonatal outcome in elective lower segment cesarean section done at 38 and 39 weeks. J Reprod Contracept Obstet Gynecol. 2017;6(4):160460.

13. Glavind J, Kindberg SF, Uldbjerg N, Khalil M, Møller AM, Mortensen BB, et al. Elective cesarean section at 38 weeks versus 39 weeks: neonatal and maternal outcomes in a randomized controlled trial. BJOG. 2013;120(9):1123-32.

14. Shetty SK, Shetty AK. Association of neonatal respiratory morbidity with the timing of elective cesarean delivery. Int J Reprod Contracept Obstet Gynecol. 2015;4(2):461-4.

15. Chunduri S, Avabrata S. Respiratory morbidity in term neonates following elective caesarean section. Int J Contemp Pediat. 2017;4(4):1142-5.

16. Cox AG, Narula S, Malhotra A, Fernando S, Wallace E, Davies-Tuck M. The influence of maternal ethnicity on neonatal respiratory outcome. Arch Dis Childhood Fetal Neonat. 2020;105(1):50-5.

17. Hourani M, Ziede F, Rajab M. Timing of planned caesarean section and the morbidities of the newborn. North Am J Med Sci. 2011;3(10):465-8.

18. Okeke TC, Onah N, Ikeako LC, Ezenyeaku CCT, Nwogu-Ikojo E. Maternal and fetal outcome of elective caesarean section at 37-38 weeks versus 39 completed weeks of gestation. Am J Clinic Med Res. 2013;1(2):32-4.

19. Prediger B, Mathes T, Polus S, Glatt A, Buhn S, Schiermeier $\mathrm{S}$, et al. A systematic review and timeresponse meta-analysis of the optimal timing of elective caesarean sections for best maternal and neonatal health outcomes. BMC Preg Childbirth. 2020;20:395-413.

Cite this article as: Rohilla $\mathrm{P}$, Goel $\mathrm{P}$, Jain $\mathrm{S}$.

Association of early neonatal-maternal outcomes with timing of elective caesarean section at term gestation. Int J Reprod Contracept Obstet Gynecol 2021;10:2403-7. 